\title{
Research on Achievement of Olympic Games
}

\author{
Xiaomeng LI \\ Department of Computer Science, North China Electric Power University, Baoding ,071000,China \\ 2952331968@qq.com
}

Keywords: Grey Prediction, Olympic Games, Gold medals

\begin{abstract}
In order to find factors affecting the achievement of national Olympic Games ,We give an accurate prediction the medals (gold medals and total medals) and final rank of the Olympic Games by constructing a Basic Prediction Model using publicly available data in order to account for the effect of the relation between historical scores and present scores. The data we can use for prediction is seldom thus we propose a Grey Prediction Model as our basic prediction model. In addition, corresponding to the Olympic results of the factors were analyzed one by one.
\end{abstract}

\section{The Research Background}

Since the first Olympic Games held in ancient Greece in April of 1894 , more and more countries and people have been keen on physical exercise and taken part in it. Olympic Games has successfully captured the world's attention. Different countries, whether developed or developing ones[1], almost all treat it as an important opportunity to show its own talent even comprehensive national power[2]. During Olympic Games duration, the rank of every country in Olympic Games has become a hot topic. Medias and authorities both at home and abroad were predicting the medals and rank of their own country and others. However, with the games' process, they found errors and adjusted their initial forecast unceasingly.

\section{The Basic Model}

Data Analysis. Before a new Olympic Games, we are able to attain previous scores. Because of the physical quality and sports investment ability of the same nation, there exists certain relation between scores of one country in different Olympic Games. Therefore, we develop a model to predict the scores and ranks in the premise of previous scores.

Firstly, collecting the previous data we find out that 1996 is a turning point to majority of countries. As for most countries, due to all kinds of factors, they did not been entitled to participate in Olympic Games [3]. After 1996, however, scores of a country remain the same trend, which differ from 1996 ago. It may be explained by the fact that world shows a brand new face entering the 21st century. The economy develops dramatically all over the world. But the speed of development varies from country to country. Some countries lead and others develop slowly. It results in change to every country. In order to predict the scores and rank well and truly, we apply the data from 1996 to 2012 Olympic Games.

In addition, we also note that the first 10 countries[4] in every Olympic Games remain constant. While other countries, ranked later, alter their own ranking over time. It results from both economic and political factors to a great extent. The first 10 countries ranked in 1996 to 2012 Olympic Games, US, UK, China, Russia, their comprehensive rank steadily in the world. Maybe this can explain its steady ranking. And small changes are allowed. But others such as developing countries still are developing greatly. So their ranking vary with their development dynamically. Moreover, a huge majority of developing countries are easily affected by changed developed countries and international political situation etc..

Description of the Basic Prediction Model. In this part, we should choose a suitable strategy of predicting rank and scores. There are many kinds of prediction methods, but different methods are suitable for different cases. So the data we can get is seldom and we lack basic data to predict future results. Fully considering those characters above, we establish a Grey Predict Model. 
The main idea of Grey Predict Model is to acquire approximate exponential law by accumulating raw data or through other ways. Its strengths is that this method does not need too much data. More importantly, it can dig deep the essence of the system by differential equation and fits for medium and short term forecast. Given all these features, we build a Grey Predict Model.

The final expression for Grey Predict Model is found as follows.

$$
\hat{x}^{(1)}(k+1)=\left(x^{(0)}(1)-\frac{\hat{b}}{\hat{a}}\right) e^{-\hat{a} k}+\frac{\hat{b}}{\hat{a}}, \quad k=0,1, \ldots, n-1, \ldots
$$

Notations and Descriptions is shown following Table 1.

Table.1 Notations and Descriptions

\begin{tabular}{c|c}
\hline Notations & Descriptions \\
\hline$x^{(0)}$ & Reference data \\
$k$ & The $k^{\text {st }}$ Games \\
$x^{(1)}(k+1)$ & Forecast to the $(k+1)^{\mathrm{st}}$ \\
\hline
\end{tabular}

\section{Implementation and Results}

The Result. These predicted results, both Gold Medals Forecast and Total medals forecast of 10 countries in Rio de Janeiro Olympic Games are presented in Figure 1-4 and shown graphically in Table 2.

The Result Analysis. Shown in table 2, our model gives a precise predict to most countries. Otherwise, there exists divergence between forecast and actual values in several countries, for example, UK, China,. The scores of China, decreased, weather may lead to the differences. Rio de Janeiro locates in South America while China lie in Asia, there are big differences between the two Chaus. It brings huge challenges for athletes from China to suit the environment of Rio de Janeiro quickly during the games. This is rational to explain the divergence between forecast and actual values.

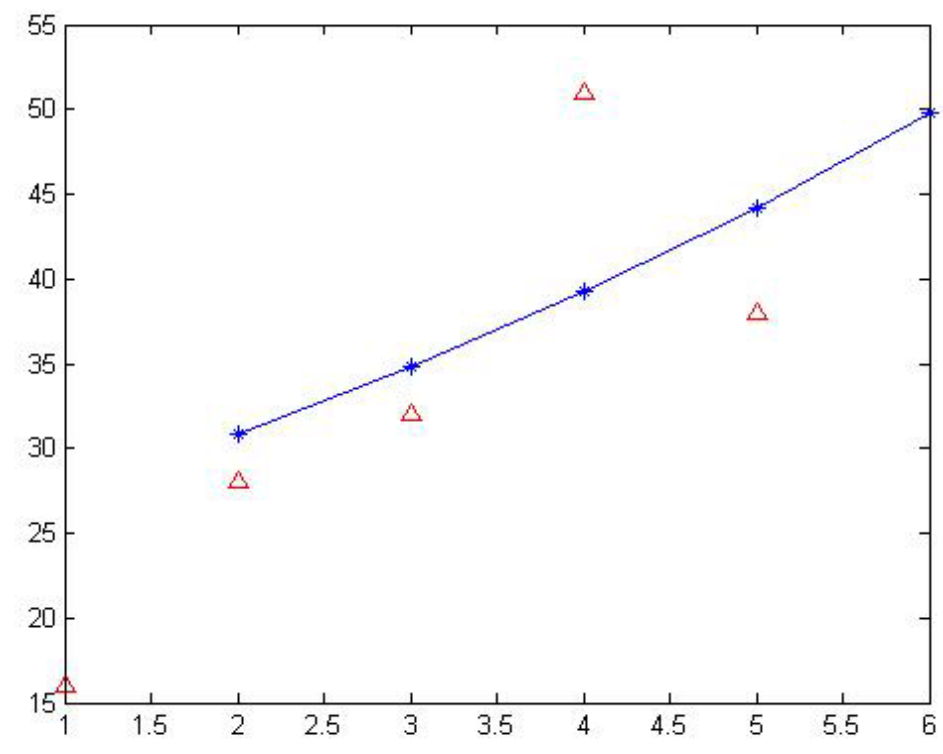

Fig.1 Gold Medals Forecast of USA 


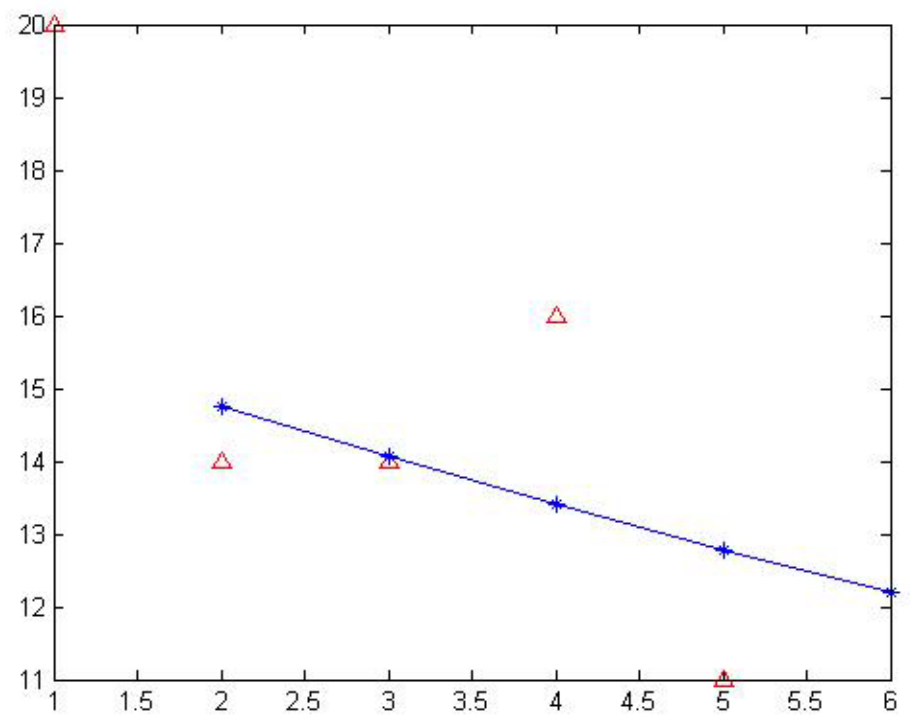

Fig. 2 Gold Medals Forecast of UK

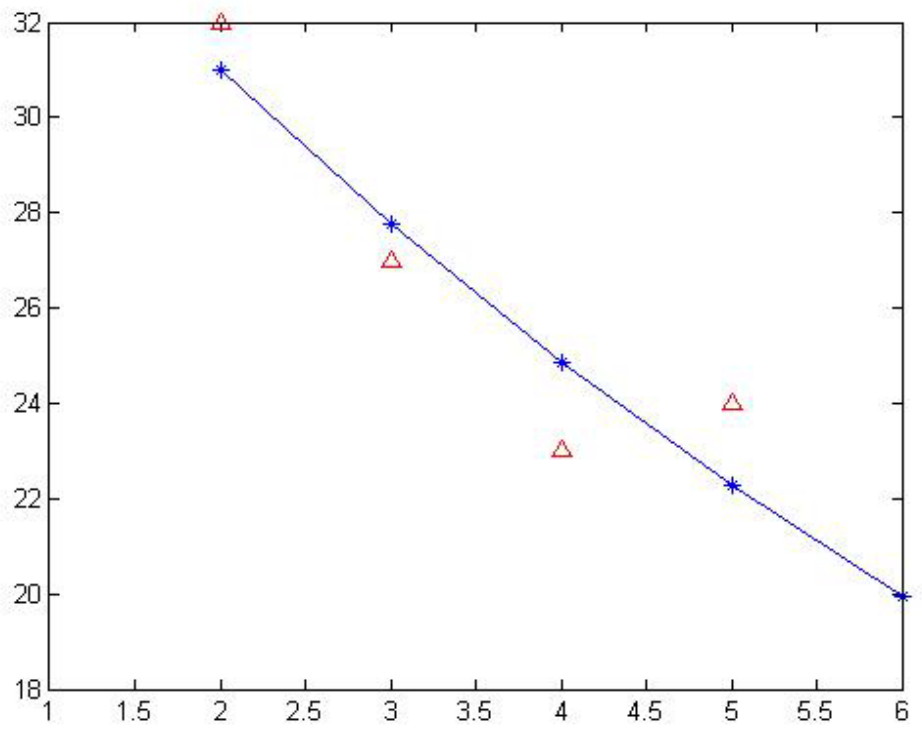

Fig.3 Gold Medals Forecast of Russia

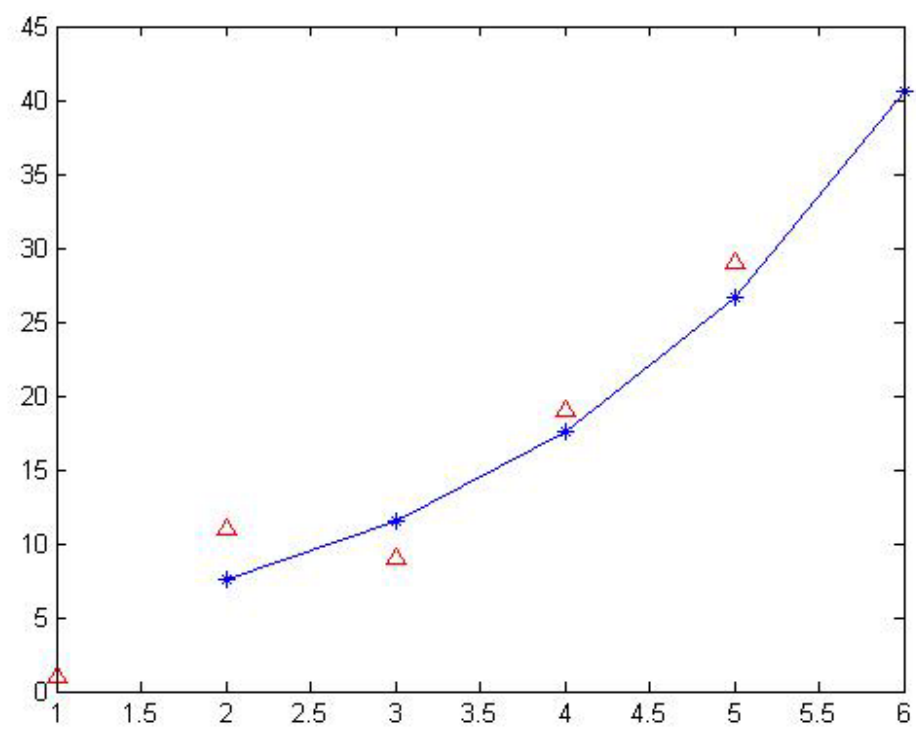

Fig.4 Gold Medals Forecast of China

$x$-axis in Figure 1-4 represents the change of the year;

$y$-axis in Figure 1-4 represents the change of the number of the Total Medal. 
Table. 2 Forecast to Rio de Janeiro Olympic Games

\begin{tabular}{|c|c|c|c|c|}
\hline & 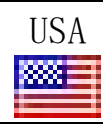 & UK & China & $\begin{array}{c}\text { Russia } \\
64 \\
50\end{array}$ \\
\hline $\begin{array}{l}\text { Gold Medal } \\
\text { Forecast }\end{array}$ & 45 & 40 & 49 & 19 \\
\hline Fitting error & 0.034 & 0.071 & 0.082 & 0.028 \\
\hline $\begin{array}{l}\text { Medal total } \\
\text { forecast }\end{array}$ & 111 & 86 & 110 & 74 \\
\hline Fitting error & 0.040 & 0.145 & 0.148 & 0.067 \\
\hline
\end{tabular}

\section{Analysis on Comprehensive National Power}

Comprehensive national power [2][5] means all the strength of a sovereign state to survive and develop, included material power, spiritual power and the international influence. It refers to the comprehensive capacity of a country to influence and handle international affairs in the international community and it is a measure of a country's position in the international community and the role .

Specifically speaking, comprehensive national power can be composed of 7 facets as follows:

Political Power. It mainly includes: political system vitality, government leadership and coordination, national cohesion, diplomatic activity, internal and external policies. It is more difficult to determine a value for the effect of political power, so in this part, we regardless of the difference within the country and assume that scores are mainly relevant to the ability of athletes.

Economic Power. It mainly compromises of economic strength[1], economic system, gross national product, international finance, import and export trade and so on. In our model, we take GDP as the main indicator of economic condition.

Science and Technology. Includes number and quality of scientific and technical personnel[6], the proportion of investment in science and technology in the gross national product, the level of high tech, etc..

Defense Force. Its main indicators consist of the quantity and quality of the armed forces, military expenditure, defense technology and defense industry.

Education Level. It involves the number and quality of teachers, the ratio of expenditure on public education to the gross national product, national cultural level. In order to measure the difficulty of migration for refugees, the index of transportation accessibility is introduced. It covers almost all factors mentioned above.

Diplomacy. Role and influence in the world and diplomatic ability of a country.

Resources. Its main measurements include national land area, geographic location[4], climate, and the population. During the process of quantitative evaluation and research, according to the definition and major characteristics of resources, the following two aspects will have a significant impact on the result: national land area and the population. They are shown following Fig 5.

Here are the main factors influencing the number of medals we take into consideration. That's because they have an effect on the economy, education, resource, technology of China. That's to say, these exert an effect on the number of medals. 


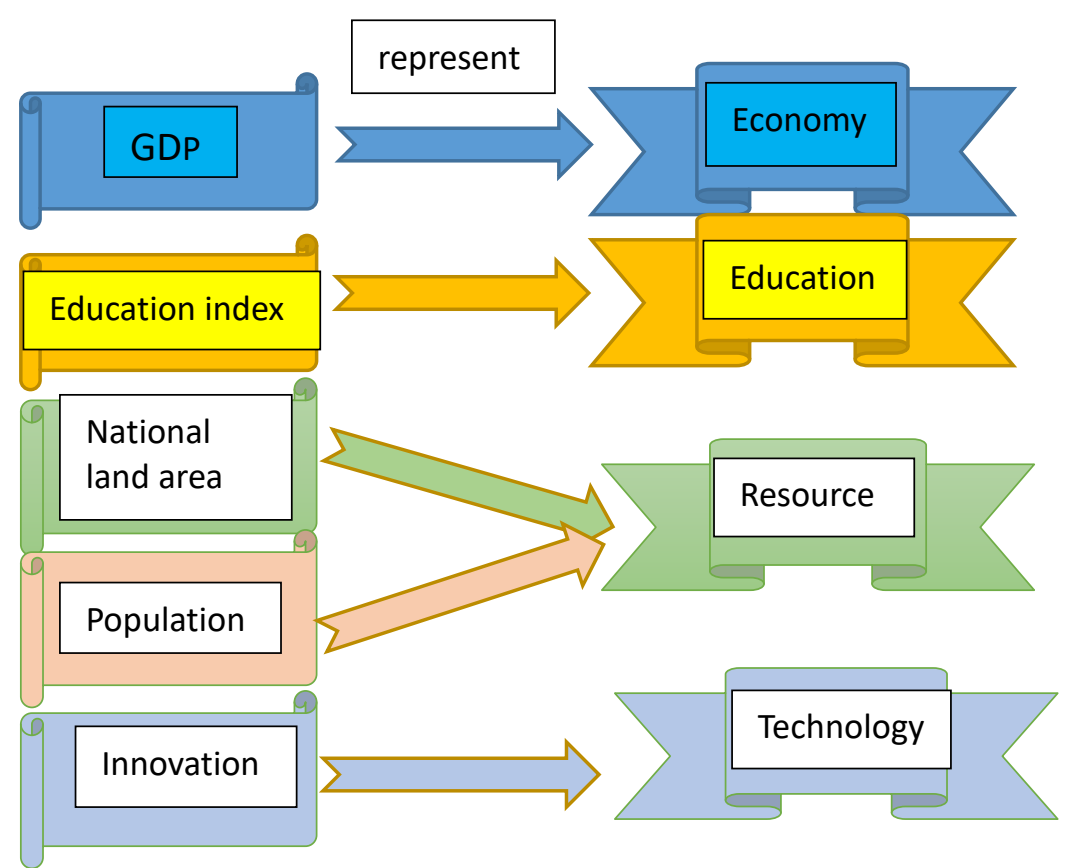

Fig.5 Indicators of each facet

\section{Conclusion}

We draw a conclusion that the comprehensive national power and whether one is the host country have an influence of the medals (gold medals and total medals) and final ranking in the Olympic Games ,by Comparing the predicted 2016-year winners and the actual winners in 2016 countries.

\section{Reference}

[1] China National Bureau of Statistics. Knowledge Economy Index. http://www.stats.gov.cn.html, 2017,1.

[2] Titter. Comprehensive national strength. http://bbs.tiexue.net/ .2012.3.

[3] National Bureau of Statistics. Informatization Development Index.

[4] Winnan. Land area of countries in the world. http://wenda.so.com. 2016.8. http://www.stats.gov.cn/ztjc/ztsj/gjsj.html. 2017.1.

[5] Aninnabl. The comprehensive national strength ranking. http://baike.so.com.2015.4.

[6] China National Bureau of Statistics. National Innovation Statistics. http://www.malaysiaeconomy.net/world_economy/\#13.2017.1. 